\title{
PREDICAÇÃO SECUNDÁRIA, MODIFICAÇÃO E AMBIGUIDADE: UMA REFLEXÃO DE BASE EMPÍRICA
}

\section{SECONDARY PREDICATION, MODIFICATION AND AMBIGUITY: AN EMPIRICAL BASED REFLECTION}

\author{
Andrea Knöpfle - Universidade Federal de Pernambuco ${ }^{1}$
}

\section{RESUMO}

Este artigo propõe uma reflexão com base em dados que tenham leitura de resultado em Português Brasileiro. Assume-se que essa língua não forma construções resultativas stricto sensu, mas apresenta estruturas de predicação secundária orientada para objeto que, muitas vezes, permitem a leitura resultativa licenciada por meio de algum tipo de modificação desse predicado, como primeiramente notado em Lobato (2004). Observa-se o contraste nos dados: (i) 'Maria pintou a casa amarela' e (ii) 'Maria pintou a casa bem amarelinha', em que, diferentemente de (i), há a leitura de resultado em (ii), efeito do intensificador 'bem' e da flexão de diminutivo. A proposta desse trabalho é expandir a investigação empírica testando outros tipos de modificação, como foco e alteração de ordem. Os resultados são comparados a outras estruturas de predicado secundário orientado para objeto, especificamente as que apresentam ambiguidade estrutural. A sugestão é de que os efeitos da modificação em estruturas como (ii) possam fazer parte de um comportamento mais abrangente na gramática, comportamento esse relacionado a estruturas de predicação secundária e ambiguidade em PB, ambiguidade essa ausente em línguas como o inglês e o alemão.

PALAVRAS-CHAVE: predicado secundário; modificação; ambiguidade; pseudoresultativa.

\begin{abstract}
This work proposes a reflection based upon data with resultative reading in Brazilian Portuguese. It is assumed that this language does not generate resultatives constructions stricto sensu, but it does form object oriented secondary predication structures which, in many cases, allow the resultative reading licensed by some sort of adjectival modification, as first noted by Lobato (2004). The contrast can be noted in the following data from BP: (i) 'Maria pintou a casa amarela' - Maria painted the house yellow - and (ii) 'Maria pintou a casa bem amarelinha' - Maria painted the house vey yellowDIMINUTIVE - in which (ii) has the resultative reading as an effect caused by the intensifier 'bem' - very - and the diminutive morphology, differently from the reading in (i). The proposal of this work it to expand the empirical investigation by testing other sorts of modifiers, such as focus and word order. The results are then compared to other object oriented secondary predication structures, specifically the ones showing structural ambiguity. The suggestion is that the effects of modification in structures such as (ii) may be part of a broader grammatical behavior related to secondary predication structures and ambiguity, having in mind the lack of such ambiguity in languages such as English and German.
\end{abstract}

KEY WORDS: secondary predication; modification; ambiguity; pseudoresultative.

${ }^{1}$ Doutora em Letras. E-mail: deaknoepfle@gmail.com 


\title{
INTRODUÇÃO
}

O objetivo desse trabalho é refletir sobre a possibilidade de um padrão comportamental nas construções de predicado secundário orientado para o objeto em Português Brasileiro (PB). Essa reflexão tem como base o levantamento empírico de estruturas com leitura de resultado, que muitas vezes só são licenciadas mediante algum tipo de modificação do predicado. Embora se assuma aqui que o PB não forme construções resultativas stricto senso, essa língua apresenta estruturas com leitura resultativa cujas condições de boa formação, em muitos casos, estão condicionadas a algum tipo de modificação do predicado. A primeira seção traz as referidas construções resultativas e estruturas similares, das quais as pseudoresultativas fazem parte. Em seguida, a segunda seção apresenta as estruturas do PB e os efeitos de modificação sobre elas. Intrigantemente, as construções possíveis em $\mathrm{PB}$ parecem não formar um grupo uniforme, diferentemente do que se observa em línguas como o inglês. No entanto, o que tais construções possuem em comum são justamente os efeitos provocados pela modificação.

Os dados em (1) exemplificam instâncias de predicação secundária em que o predicado secundário atribui propriedade a um DP Acusativo, e essa propriedade tem leitura de estado resultante acionado pelo evento denotado no verbo.

\author{
a. He hammered the metal flat. (inglês) \\ Ele martelou o metal plano. \\ 'Ele deixou o metal plano/achatado, martelando-o.' \\ b. Maria picou a salsa bem fininha.
}

Para (1a), o estado resultante do ato de martelar é o metal plano/achatado, em que a propriedade plano/achatado é atribuída ao sintagma o metal como resultado do evento martelar. Para (2b), o estado resultante do ato de picar é a salsa bem fininha, sendo que a propriedade bem fininha incide sobre a salsa (ou o picado da salsa, como veremos melhor na segunda seção).

Inicialmente, portanto, as observações empíricas foram realizadas em estruturas com leitura de resultado, com o intuito de buscar uma explicação para o porquê da necessidade de modificação para a obtenção da leitura resultativa em PB. Olhando para as demais estruturas de predicação secundária, vale lembrar que o $\mathrm{PB}$ apresenta em muitas delas ambiguidade estrutural entre a leitura predicativa e a depictiva (a que nome e adjetivo formam um mesmo constituinte), assunto da terceira seção. No entanto, à medida que procedemos à modificação nesses casos, a leitura predicativa é possível. Assim, o que o presente trabalho sugere é que esse fato está relacionado com as condições de licenciamento das estruturas com leitura resultativa em $\mathrm{PB}$, notadamente de predicado orientado para o objeto, conforme se argumenta na terceira seção. Finalmente, resumem-se os resultados empíricos obtidos e as reflexões feitas, levantando algumas hipóteses para investigação. Neste artigo, a base teórico-metodológica para traçar generalizações empíricas se fundamenta em uma metalinguagem formal explícita advinda da Teoria GerativoTransformacional, em sua versão de Princípios e Parâmetros pré-minimalista (CHOMSKY, 1981, 1986, 1993, 1995; CHOMSKY e LASNIK, 1993; RIZZI, 1990, inter alia).

\section{Sobre resultativas e pseudoresultativas}

Línguas como o inglês, alemão e holandês formam produtivamente o que se chama na literatura técnica de construções resultativas (CARRIER \& RANDALL, 1992; LEVIN \& RAPPAPORT, 1995; HOEKSTRA, 1988, 1991, 1994; KRATZER, 2005 inter alia), geralmente tratadas como um tipo de construção com semântica causativa. Nelas, o verbo principal (V) denota uma ação (cujo agente é expresso pelo sujeito $\left(\mathrm{DP}_{\mathrm{NOM}},\right)$ ), e o estado resultante da ação é denotado pela combinação de um sintagma adjetival (AP) ou ainda preposicional e um DP Acusativo

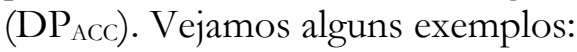


(2) a. He painted the house yellow. (inglês)

Ele pintou a casa amarelo $^{2}$

'Ele pintou a casa, que ficou amarela.'

b. He drunk the teapot empty. (inglês)

b'. Er trank die Teekanne leer. (alemão)

Ele bebeu a chaleira vazio

'Ele esvaziou a chaleira, bebendo todo o seu conteúdo.'

c. Hij schreeuwde zijn keel rauw. (bolandês)

c'. He screamed his throat sore. (inglês)

Ele gritou sua garganta machucado/inflamado. inflamada.'

'Ele gritou (tanto/de forma tal) que sua garganta ficou machucada/

Descritivamente, o DP AcC denota a entidade que sofre a ação denotada pelo verbo, e o resultado desta ação é denotado pelo AP ou PP. Hoekstra (1988) coloca a generalização empírica

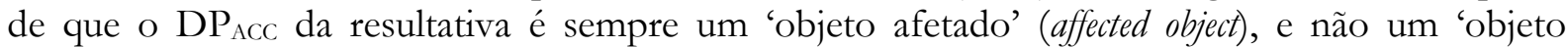
alcançado' (effected object). Nesse sentido, o 'objeto afetado' preexiste à ação verbal. O autor nota que verbos como paint (em to paint a house) são ambíguos nesse sentido, por poderem tomar como complemento tanto um 'objeto afetado' quanto 'objeto alcançado'. Porém, em uma resultativa como em (2a), tal ambiguidade não se coloca, uma vez que o DP the house é 'objeto afetado' pela ação verbal.

O DP Acc pode ou não ser interpretado como objeto (tema) do verbo. Em (2a), essa interpretação é possível (assim como para (1a)), diferentemente de (2b, b') e $\left(2 \mathrm{c}, \mathrm{c}^{\prime}\right){ }^{4}$ Informalmente, podemos nos referir a elas como resultativas 'transitivas' e 'intransitivas'.

Existe uma tradição na literatura de que línguas românicas não licenciam construções resultativas (KRAZTER, 2005; KNÖPFLE, 2014 inter alia). Os dados negativos em (3) evidenciam essa linha de argumentação.

(3) a. *Ele martelou o metal plano/achatado.

Sentido pretendido: 'Ele martelou de forma que o metal ficou plano.'

b. $\quad *$ Ele pintou a casa amarela ${ }^{5}$.

Sentido pretendido: 'Ele pintou a casa, que ficou amarela.'

c. *Ele bebeu a chaleira vazia.

Sentido pretendido: 'Ele esvaziou a chaleira, bebendo o seu conteúdo.'

e. $\quad$ *Ele gritou sua garganta machucada/inflamado.

Sentido pretendido: 'Ele gritou (tanto/de forma tal) que sua garganta ficou machucada/

inflamada.'

\footnotetext{
${ }^{2}$ Nas minhas glossas para o PB, o leitor vai notar que os adjetivos estão, aparentemente, na forma masculina e singular. Minha intenção, no entanto, é representar o adjetivo sem marcas de flexão/concordância de gênero e número. Pensando em uma abordagem à la Mattoso Camara Jr. (1970), o adjetivo das glossas não tem o sufixo flexional ou desinência $-a$ (marcador de feminino) nem $-s$ (marcador de plural); crucialmente, esse adjetivo também não teria o morfema zero marcador de singular nem o morfema zero marcador de masculino.

${ }^{3}$ Exemplo baseado em Kratzer (2005).

${ }^{4}$ Por razões de escopo e espaço, não vou elaborar sobre a transitividade do verbo em resultivas, mesmo porque se trata de uma questão controversa. Remeto o leitor interessado a Hoekstra (1988), Levin e Rappaport (1995), Kratzer (2005) e Knöpfle (2014).

${ }^{5}$ Nos dados do PB, apresento o adjetivo flexionado em gênero/número com o DP Acc. A justificativa é que, em um ambiente desse tipo (a exemplo de construções com adjetivos predicativos depictivos), o predicado secundário orientado para o objeto é flexionado em gênero/número em PB. A quarta seção elabora essa questão.
} 
Apesar de as estruturas acima não serem possíveis em PB (e línguas românicas), existem outras estruturas que apresentam a leitura, a partir de um verbo, de resultado sobre um DP. Essas estruturas foram objeto de estudo de autores como Foltran (1999) e Lobato (2004), como exemplificam os dados em (4).
a. Ele cortou o cabelo curto.
b. Ele desenhou o círculo torto.
c. Ele fabricou a cadeira torta. ${ }^{6}$
d. Ela costurou a saia justa.
e. $\quad$ engenheiro construiu a ponte sólida.
f. Deus criou os homens fracos.

Foltran (1999) analisa os dados do PB e apresenta restrições de produção em relação às construções resultativas encontradas em línguas como o inglês, por exemplo. A primeira diferença apontada pela autora é de ordem aspectual: em $\mathrm{PB}$, os predicados secundários não têm a propriedade de transformar um evento não delimitado em delimitado, diferentemente das resultativas do inglês, como hammer the metal flat - uma resultativa (prototípica) do inglês. Nela, podemos observar que o sintagma resultativo flat (plano/achatado) adiciona telicidade ao evento de hammer (martelar), que por si só seria uma eventualidade do tipo ação, sem um ponto final implícito. Ou seja, a adição do sintagma resultativo nas sentenças no PB não altera a classe aspectual do verbo, sendo que o predicado secundário parece fornecer uma descrição mais exata do estado final. Foltran (1999) nota que não são encontradas em PB resultativas com verbos de atividade (como run e drink, correr e beber) com ponto final indeterminado.

Dados a exemplo de (4a), cuja estrutura [V DP ACC $\mathrm{AP}]$ se assemelha à estrutura das resultativas, foram analisados por autores como Parsons (1990), Geuder (2000), Kratzer (2005), Levinson $(2007,2010)$, inter alia. A proposta quando da abordagem dessas estruturas era a de diferenciá-las das construções resultativas e, consequentemente, propor às primeiras alguma abordagem analítica.

Levinson $(2007,2010)$ analisa os adjetivos em (5) como modificadores de nome, ${ }^{8}$ sendo semanticamente distintos dos predicados resultativos; por esse motivo, a autora chama as construções em (5) de pseudoresultativas, e argumenta que pseudoresultativas não devem se confundir nem com resultativas adjetivais (hammer the metal flat) nem com resultativas adverbiais (They loaded the cart heavily). ${ }^{\text {? }}$

$$
\begin{aligned}
& \text { a. Mary braided her hair tight. } \\
& \text { Mary trançou seu cabelo firme/apertado } \\
& \text { 'Mary trançou seu cabelo bem firme.' } \\
& \text { b. Mary piled the cushions high. } \\
& \text { Mary empilhou as almofadas alto } \\
& \text { 'Mary empilhou as almofadas alto.' } \\
& \text { c. Mary chopped the parsley fine. } \\
& \text { Mary picou a salsa fino } \\
& \text { 'Mary picou a salsa fininha.' } \\
& \text { d. Mary sliced the bread thin. }{ }^{10}
\end{aligned}
$$

\footnotetext{
${ }^{6}$ Exemplos de Foltran, (1999, p.149-151).

${ }^{7}$ Lobato (2004, p.158,162,163).

${ }^{8}$ Levinson $(2007,2010)$ analisa os adjetivos de pseudoresultativas como modificadores de um indivíduo criado. Esse indivíduo modificado nas pseudoresultativas é analisado como sintaticamente ativo e denotado na raiz lexical do verbo. 9 'Eles carregaram o caminhão pesadamente/com muito peso'. Geuder (2000) analisa estruturas desse tipo e as chama de resulativas adverbiais.

${ }^{10}$ Exemplos de Levinson (2007, p.32).
} 
Mary fatiou o pão fino

'Mary fatiou o pão bem fino.'

No exemplo prototípico da autora Mary braided her hair tight (5a), o adjetivo não modifica o objeto direto; ou seja, o que se torna tight (firme, apertado) por meio do verbo braid (trançar) não é o objeto direto the hair (o cabelo), mas sim the braid (a trança), criada pelo evento de braiding (trançar). ${ }^{11}$ Diferentemente, em hammer the metal flat (martelar o metal plano), the metal (o metal) se torna flat (plano) como resultado do evento de martelar.

Levinson aponta uma característica semântica nos verbos em (5): eles pertencem ao grupo que a autora denomina root creation verbs. Os root creation verbs exigem uma fonte (hair, cushions, parsley - cabelo, almofadas, salsa); nesse sentido, em She braided her hair (5a), the hair seria a 'fonte' e the braid seria o 'alvo'. Em outros termos, em She braided her hair, há a interpretação de que do cabelo foi feita uma trança. A autora também traz como argumento para distinguir resultativas adjetivais de pseudoresultativas a variação translinguística. Nesse sentido, línguas românicas, reconhecidas por não apresentarem resultativas adjetivais, licenciam construções pseudoresultativas. Entretanto, quando observamos as traduções para o PB em (5), notamos a presença de algum tipo de modificador no predicado secundário - assunto que será explorado na próxima seção.

\section{Modificação e seu efeito em PB}

Lobato (2004) afirma que o PB não é capaz de licenciar estruturas como hammer the metal flat, na qual a interpretação de flat é a propriedade que o metal adquire após a ação de hammer. No entanto, a autora questiona se apenas com base em dados desse tipo se pode fazer a generalização de que as construções resultativas não existem no PB. Discordando dessa generalização, Lobato (2004) lista as condições para licenciamento da construção resultativa em PB. O adjetivo, para permitir a leitura resultativa, pode aparecer nas formas básica, superlativa e superlativa sintética, ou seja, a modificação adjetival pode licenciar determinadas resultativas, como mostra o paradigma em (6):
a. $\quad *$ João pintou a casa amarela. ${ }^{12}$
b. João pintou a casa muito amarela.
b. João pintou a casa amarelinha, amarelinha.
c. João pintou a casa bem amarelinha.
d. João pintou a casa bem amarelíssima. ${ }^{13}$
f. João pintou amarela a casa.
g. João pintou a casa AMARELA. ${ }^{14},{ }^{15}$

A questão é se podemos estender o fato apontado no dado (6) para outras resultativas. Em (7), listo o tipo de modificação que poderia, por hipótese, licenciar a leitura resultativa em PB.

\footnotetext{
11 Com uma análise morfossemântica e dentro do quadro da Morfologia Distribuída, a autora argumenta que os predicados de pseudoresultativas não modificam nenhuma palavra na sintaxe, mas sim a raiz do verbo em uma configuração licenciada pelo tipo semântico da raiz e pela estrutura de verbos que a autora chama de root creation verbs. 12 Agramatical na leitura relevante, i.e. 'a casa se torna amarela como resultado da ação de pintar'. Porém, na leitura depictiva (i.e. $\mathrm{N}$ e A formam um constituinte), o dado é gramatical.

13 Exemplos de Lobato (2004, p.152,158,159).

${ }^{14}$ Incluí os dados em (6f-g), em que a alteração da ordem NOME - ADJETIVO e foco parecem contribuir para a aceitabilidade da leitura resultativa.

$15 \mathrm{O}$ dado João pintou a casa de amarelo não é considerado como resultativa por Lobato (2004), pois a informação do adjetivo especifica a cor, e essa informação é redundante para a estrutura temporal do evento, i.e. o predicado secundário não delimita o evento, tornando-o télico (conferir telicidade ao evento é condição para o predicado secundário formar uma resultativa, na concepção da autora).
} 
(7) a. quantificadores/intensificadores/advérbios/PPs. Exs.: toda amarela, super amarela, amarela pra caramba.

b. $\quad$ iteração do adjetivo. Exs.: amarela-amarela.

c. morfologia flexional em grau no adjetivo. Exs.: amarelinha, amarelona, amarelíssima.

d. Ordem e foco: amarela a casal a casa AMARELA.

A modificação interfere na aceitabilidade de alguns dados do PB, construídos com base nas resultativas 'transitivas' das línguas como o inglês, alemão e holandês. ${ }^{16}$

(8) a. *Ele martelou o metal plano/achatado.

b. Ele martelou o metal super plano/super achatado. ${ }^{17}$

c. Ele martelou o metal plano pra caramba/achatado pra caramba.

d. Ele martelou o metal completamente plano/ completamente achatado.

(9) a. *Ele varreu o chão limpo.

b. Ele varreu o chão limpinho/ bem limpinho.

c. Ele varreu o chão limpo pra caramba.

As possibilidades de modificação são várias, e se admite algum grau de variação no julgamento dos dados. No entanto, restam dados bem formados licenciados pela modificação. Entretanto, para resultativas 'intransitivas', a modificação não 'salva' a construção.

(10) a. *Ele bebeu a chaleira vazia.

b. *Ele bebeu a chaleira super vazia/ vazia, vazia/ vazia pra caramba.

c. *Ele bebeu a chaleira bem vazia/ toda vazia/ quase vazia.

(11) a. *Ele correu os sapatos estragados.

b. $\quad *$ Ele correu os sapatos super estragados / estragados pra caramba.

c. *Ele correu os sapatos estragadinhos/ estragadíssimos/ bem estragadinhos.

e. $\quad *$ Ele correu os sapatos bem estragados/ todo estragados/ quase estragados.

Os dados do PB moldados com base em resultativas 'intransitivas' ou 'transitivas', mas cujo $\mathrm{DP}_{\mathrm{ACC}}$ não é tema do verbo, não possíveis em $\mathrm{PB}$, mesmo com modificação. Porém, como vimos em (6), (8) e (9), os dados em PB feitos com verbos transitivos e $\mathrm{DP}_{\mathrm{ACC}}$ tema desses verbos são possíveis (leitura resultativa) com modificação. A questão, portanto, é se de fato não existem resultativas em $\mathrm{PB}$, mesmo que restritas a verbos transitivos e modificação adjetival. A resposta para essa questão é negativa e tem base empírica no contraste com exemplos do alemão e do PB:

(12) a. Hans hat den Fussboden sauber gefegt.

Hans teve o chão limpo varrido.

'Hans varreu o chão, e o chão ficou ficou limpo.'

b. Hans hat den Fussboden schmutzig gefegt.

Hans teve o chão sujo varrido.

'Hans varreu o chão, e o chão ficou sujo.' (porque o João usou uma vassoura suja, que acabou lambuzando o chão, que ficou mais sujo do que estava antes de ser varrido.)

(13) a. João varreu o chão bem limpinho.

${ }^{16}$ Seguem as resultativas (prototípicas da literatura técnica) a partir das quais os testes para o PB foram moldados:

(i) He hammered the metal flat.

(ii) He swept the floor clean.

${ }^{17}$ Comportamento semelhante também é encontrado em outras línguas românicas, a exemplo do italiano:

(i) Gianni ha martellato il metallo *piatto/ piatto, piatto. (FOLLI\&RAMCHAND, 2005, p.15) 
$\rightarrow$ João varreu o chão, e o chão ficou bem limpinho.

b. $\quad$ *João varreu o chão bem sujinho. (na leitura resultativa)

$\neq \rightarrow$ João varreu o chão, e o chão ficou bem sujinho. (porque o João usou

uma vassoura suja, que acabou lambuzando o chão, que ficou mais sujo do que estava antes de ser varrido.)

Observamos que a mesma estrutura e sentido possíveis na resultativa do alemão não são possíveis em PB. Em PB, o dado (13b) é agramatical na leitura em que o chão resulta sujo como consequência do ato de varrer, diferentemente da resultativa em (12b) no alemão. Ou seja, se tivéssemos o mesmo tipo de estrutura em (12) e (13), esse contraste não seria esperado. $\mathrm{O}$ paradigma em (12)-(13) reforça a ideia de que, em PB, o AP é uma espécie de modificador, diferentemente de resultativas, em que denota o estado final. Diante dos fatos em (12)-(13), a conclusão é a de que o PB não licencia a estrutura das construções resultativas como em línguas como alemão, inglês e holandês. Dito de outra forma, as estruturas transitivas com leitura de resultado que o $\mathrm{PB}$ apresenta, portanto, são de outra natureza.

Resumindo, em PB, modificação do A licencia a leitura resultativa para alguns tipos de construção, mas não licencia a construção resultativa stricto sensu. Retomemos agora as pseudoresultativas (ou similares) em PB.

Os dados de Levinson (2007) em (5), chamados pela autora de pseudoresultativas, quando traduzidos para o PB, precisam de modificação no A para serem licenciados. Vejamos:

(14) a. He chopped the parsley fine.

Ele picou a salsa fino

b. $\quad *$ Ele picou a salsa fina.

c. Ele picou a salsa fininha.

(15) a. Mary ground the coffee beans fine.

Mary moeu os café grãos fino

b. $\quad *$ Mary moeu os grãos de café finos.

c. Mary moeu os grãos de café bem fininhos.

Os dados em (14b) e (15b) são agramaticais na leitura resultativa, i.e. a salsa ou o picado da salsa ficou fino e os grãos de café ou o picado dos grãos de café ficou fino. É preciso que haja algum tipo de modificação no A para que a leitura resultativa seja possível, conforme verificamos nas sentenças em $(14 c)$ e (15c). da construção.

Além da modificação no A, ordem e foco também parecem colaborar para o licenciamento

(16) a. Mary braided her hair tight.

b. *Maria trançou seu cabelo firme.

c. Maria trançou seu cabelo bem firme.

d. Mary trançou firme seu cabelo.

e. Mary trançou seu cabelo FIRME.

(17) a. Mary tied her shoelaces tight.

b. ?Mary amarrou o cadarço dela apertado.

c. Mary amarrou o cadarço dela bem apertado.

d. Mary amarrou apertado o cadarço dela.

e. Mary amarrou o cadarço dela APERTADO.

(18) a. Mary chopped the parsley fine.

b. *Mary picou a salsa fina

c. Mary picou a salsa fininha. 
d. Maria picou fina a salsa.

e. Maria picou a salsa FINA. ${ }^{18}$

(19) a. Mary sliced the bread thin.

b. * Mary fatiou o pão fino.

c. Mary fatiou o pão bem fino.

d. Maria fatiou fino o pão.

e. Maria fatiou o pão FINO.

Entretanto, não são todas as pseudoresultativas que precisam de modificação para licenciar a leitura resultativa. Notamos que em (20b), diferentemente do que observamos para os outros dados, não é possível fazer a concordância em gênero e número com o $\mathrm{DP}_{\mathrm{ACC}}$
a. Mary piled the cushions high.
Mary empilhou as almofadas alto
b. Mary empilhou as almofadas alto/*altas.

Temos, adicionalmente, os dados de Foltran (1999) e Lobato (2004), com predicação secundária orientada para o objeto, que não precisam de modificação para licenciar a leitura resultativa. Eles são repetidos aqui em (21):

(21) a. Ele cortou o cabelo curto.

b. Ele desenhou o círculo torto.

c. Ele fabricou a cadeira torta.

d. Ela costurou a saia justa.

e. $\quad$ O engenheiro construiu a ponte sólida.

f. Deus criou os homens fracos.

Se tomarmos como base a análise de Levinson, os dados em (21) teriam uma descrição estrutural distinta das pseudoresultativas. Fato é que, em PB, os dados em (21) são estruturas em que os adjetivos podem ser tomados como predicado secundário orientado para o objeto sem a necessidade de modificação e, uma vez predicados secundários, podem ter leitura resultativa. Diferentemente, as pseudoresultativas quando traduzidas para o PB precisam de tal modificação, pelo menos a maioria delas. Admitindo, por hipótese, que se trate de dois grupos com descrições estruturais distintas, ainda assim não temos uma uniformidade de comportamento nas pseudoresultativas do $\mathrm{PB}$ quando da comparação com o inglês e mesmo dentro do próprio $\mathrm{PB}$. $\mathrm{O}$ paradigma em (20) evidencia a não concordância do adjetivo e a não necessidade de modificação, diferentemente dos dados em (14) a (19).

Adicionalmente, temos as estruturas do PB com leitura de resultado, traduzidas das resultativas stricto sensu 'transitivas', em que todas elas somente são licenciadas mediante modificação do A. Essas estruturas não têm a mesma interpretação semântica tomada na análise de Levinson: os $\mathrm{DP}_{\mathrm{ACCS}}$ são objetos afetados e não criados. Em outras palavras, teríamos aqui, por hipótese, um terceiro grupo.

A questão que se coloca nesse ponto é: o que têm essas estruturas em comum, à medida que o licenciamento (de muitas delas) se dá mediante algum tipo de modificação no adjetivo?

A sugestão é que o que quer que licencie a leitura resultativa em PB pode ter relação com algum fenômeno mais abrangente nas estruturas de predicação secundária orientada para o objeto,

18 Possivelmente, a concordância não é necessária aqui:

(i) Mary picou a salsa fininho.

(ii) Maria picou fino a salsa.

(iii) Maria picou a salsa FINO.

Revista do GELNE, Natal/RN, Vol. 19 - Número 2: p. 101-113. Jul-Dez. 2017 
especificamente na ambiguidade que se observa em PB entre construção predicativa e depictiva, assunto da próxima seção.

\section{Ambiguidade em PB}

As pseudoresultativas (e similares) podem ser tomadas como um subgrupo das estruturas que envolvem predicação secundária orientada para o objeto. Assim, é importante ter em mente que para a possibilidade de leitura resultativa é imprescindível que se trate de uma estrutura em que AP seja um predicado secundário. Os dados do PB que foram asteriscados indicando agramaticalidade faziam referência justamente à leitura resultativa. Se, diferentemente, estivessem sendo julgados quanto à leitura depictiva, seriam aceitáveis. Nessa última estrutura, nome e adjetivo fazem parte do mesmo constituinte sintático.

Olhando agora para além das estruturas com interpretação de resultado, temos reconhecidamente estruturas com a sequência tipicamente não descontínua [V(verbo) $\mathrm{N}$ (nome) A (adjetivo)] que apresentam ambiguidade entre a leitura em que $\mathrm{N}$ e $\mathrm{A}$ formam um único constituinte (depictiva) e a leitura em que $\mathrm{N}$ e $\mathrm{A}$ estão em constituintes diferentes (predicativa). Assim, a ambiguidade observada na sequência é gerada por duas descrições estruturais distintas: a estrutura depictiva e a predicativa. Vejamos alguns dados:
a. João comeu a carne crua. ${ }^{19}$
b. $\quad$ Foi a carne crua que João comeu.
c. Foi crua que João comeu a carne.
d. Foi a carne que João comeu crua.
a. Maria comprou a maçã verde.
b. $\quad$ Foi a maçã verde que Maria comprou.
c. Foi verde que Maria comprou a maçã.
d. Foi a maçã que Maria comprou verde.

A sequência em (22a) representa duas sentenças diferentes, geradas cada uma por uma descrição estrutural distinta. Em uma delas, representada pela paráfrase em (22b), a carne forma um constituinte com crua, i.e. o DP [a carne crua]. Em outra descrição estrutural, representada nas paráfrases em (22c) e (22d), a carne não forma um DP com crua, pois estão em constituintes distintos. O mesmo raciocínio vale para o paradigma em (23). É interessante notar que essa ambiguidade, estruturalmente comprovada, não parece ser tão óbvia quando submetida a julgamentos de aceitabilidade, em que a interpretação mais saliente é a depictiva. Inclusive, algumas vezes, é necessário recorrer a exemplos como ele comen a carne crua mal passada ${ }^{20}$ para que se evidencie a diferença das estruturas. Esse tipo de ambiguidade não se verifica em línguas como o inglês ou o alemão. ${ }^{21}$
a. John ate the meat raw. (inglês)
John comeu a carne crua.
'John comeu a carne crua.' (leitura predicativa)

b. John ate the raw meat.

\footnotetext{
19 Para uma proposta atual de análise gramatical para estruturas de predicação secundária, remeto o leitor a Carreira (2015).

${ }^{20}$ Esse exemplo poderia fazer referência a um contexto em que, entre as carnes disponíveis, foi preparada a carne crua, para fazer carne de onça ou tartar, por exemplo. Mas o cozinheiro desajeitado acabou perdendo o ponto da carne crua, que ficou mal passada.

21 Carreira e Knöpfle (2013) fazem um trabalho de comparação translinguística entre estruturas de predicação secundária orientada para objeto, tomando as línguas PB e alemão.
} 
John comeu a crua carne.

'John comeu a carne crua.' (leitura depictiva)

Em inglês, na estrutura predicativa, $\mathrm{N}$ precede $\mathrm{A}$, diferentemente da estrutura depictiva, em que A precede N. A diferença de estrutura em relação ao PB fica ainda mais clara quando da comparação com o alemão, quando observamos as marcas morfológicas de caso, gênero e número nessa língua:
a. Hans ass das
Fleisch roh. (alemão)
Hans comeu ARTIGO-NEUTRO-ACC-sING carne cru
'Hans comeu a carne crua'.' (leitura predicativa)
b. Hans ass das rohe Fleisch.
Hans comeu artigo-NEUTRO-ACC-SING CruneUtro-ACC-SING carne
'Hans comeu a carne crua'.' (leitura depictiva)
a. Hans kaufte den
Apfel grün.
Hans comprou ARTigo-MASCULINO-ACC-SING maçã verde
'Hans comprou a maçã verde.' (leitura predicativa)
b. Hans kaufte den grünen Apfel.
Hans comprou ARTIGO-MASCULINO-ACC verde MASCULINO-ACC-SING maçã 'Hans comprou a maçã verde.' (leitura atributiva)

Notamos que em (25a) e em (26a) o adjetivo está posposto ao nome e não concorda com ele; aliás o adjetivo não apresenta nenhuma marca de gênero ou caso. Diferentemente, em (25b) e (26b), o adjetivo se antepõe ao nome e flexiona em gênero, número e caso de acordo com esse nome. A gramática tradicional do alemão descreve os adjetivos como adjetivos em uso predicativo e adjetivos em uso atributivo (que eu chamei aqui de depictivo). No primeiro caso, o adjetivo nunca é anteposto ao nome e não pode flexionar. No segundo caso, o adjetivo sempre é anteposto ao nome e concorda com ele.

Ou seja, o PB, diferentemente de línguas como inglês e alemão, apresenta a ambiguidade entre a leitura predicativa e a atributiva. No entanto, se procedermos à modificação do adjetivo, parece que é a leitura predicativa a mais saliente. ${ }^{22}$

(27) a. João comeu a carne quase crua.

b. João comeu a carne bem crua.

c. João comeu a carne crua pra caramba.

(28) a. Maria comprou a maçã quase verde.

b. Maria comprou a maçã bem verde.

c. Maria comprou a maçã verde pra caramba.

Quando a modificação em questão for foco ou inversão de ordem, então a leitura predicativa é a única possível, o que evidencia a estrutura como sendo predicativa de fato. ${ }^{23}$

(29) a. João comeu a carne CRUA.

22 Trata-se de uma questão empírica se a leitura depictiva está disponível. É possível que não esteja, evidenciando se tratar de uma estrutura predicativa. Por ora, deixo essa questão em aberto.

${ }^{23} \mathrm{O}$ que não é surpreendente, pois esse tipo de modificação só é possível para A se ele não fizer parte do DP que contém N. 
b. João comeu crua a carne.

(30) a. Maria comeu a maçã VERDE.

b. Maria comeu verde a maçã.

Os dados de Foltran (1999) e Lobato (2004), a rigor, também podem ter leitura depictiva. Igualmente, quando se procede à modificação, parece ser a leitura predicativa a mais saliente.

(31) a. Ele cortou o cabelo bem curtinho.

b. Ele desenhou o círculo torto pra caramba.

c. Ele fabricou a cadeira super torta.

d. Ela costurou a saia quase justa.

e. $\quad$ O engenheiro construiu a ponte sólida, sólida.

f. Deus criou os homens fraquíssimos.

Ao que tudo indica, o efeito da modificação parece ser o de evidenciar a leitura predicativa. Quando há essa leitura, trata-se de uma estrutura predicativa. Assim como para os dados em (27) e (28), fica em aberto se a leitura depictiva ainda está disponível, questão essa que requer mais testes.

\section{CONSIDERAÇÕES FINAIS}

Esse trabalho investigou as estruturas com leitura de resultado em PB. Essa língua não forma construções resultativas stricto sensu, diferentemente de línguas ocidentais germânicas como o inglês, alemão e holandês - conforme demonstrado. Entretanto, restam estruturas que possuem alguma leitura de resultado, sendo elas um subgrupo das estruturas de predicação secundária. Algumas das estruturas apresentam a leitura de resultando mediante algum tipo de modificação sobre o adjetivo (predicado secundário), a saber: intensificadores, morfologia adjetival, ordem e foco. As estruturas com leitura de resultado não formam um grupo uniforme em termos desse comportamento; entretanto, a modificação evidencia a leitura de resultado. Adicionalmente, com base nas propriedades semânticas dos verbos e dos predicados secundários, parecem existir três grupos de estruturas com leitura de resultado, dentre os quais as pseudoresultativas fazem parte.

A conclusão, até agora, é de que a modificação (intensificador e morfologia adjetival) tem como efeito salientar a leitura predicativa em sequências ambíguas entre a leitura predicativa e a depictiva. Os dados com interpretação resultativa, em sendo um subgrupo de estruturas de predicação secundária orientada para objeto, parecem seguir essa generalização empírica.

Se essa linha de raciocínio estiver na direção correta, uma hipótese a ser investigada é a de que a modificação não seria um recurso que licencia propriamente a estrutura predicativa com leitura de resultado em PB, mas, antes disso, a modificação salienta a estrutura predicativa já disponível na língua. Em outros termos, teríamos aqui uma questão de gramaticalidade versus aceitabilidade. Para elucidar a questão, retomemos alguns exemplos.

(32) a. João pintou a casa amarela.

b. João pintou a casa bem amarelinha.

A sequência em (32a) representaria duas estruturas: (i) o adjetivo forma um DP com o nome, formando a leitura depictiva; (ii) o adjetivo é um predicado secundário orientado para o objeto. Ou seja, ambas as estruturas seriam gramaticais, i.e. são geradas pelas regras gramaticais da língua. Como a leitura/interpretação é, a priori, a depictiva, então essa leitura é a aceitável, sendo a leitura predicativa (e consequentemente resultativa) inaceitável. Essa leitura inaceitável se torna aceitável em (32b), quando a modificação evidencia a leitura predicativa, resultado da estrutura 
predicativa. Se a estrutura predicativa não estivesse disponível na língua (i.e. no dado (32a)), então eu me pergunto como a modificação acessaria tal estrutura, tornando-a gramatical (dado (32b)).

Essa é uma hipótese; outra seria a de que (32a) é agramatical para a estrutura predicativa, sendo a modificação responsável por licenciar a estrutura predicativa (e a consequente interpretação de resultado). No entanto, acredito que a primeira hipótese ainda seja a mais plausível por dois motivos. O primeiro deles é que a modificação não atua de forma uniforme em todas as estruturas de predicação secundária em $\mathrm{PB}$. O segundo motivo, decorrente do primeiro, leva em conta uma gramática com regras as mais generalizáveis e econômicas do ponto de vista computacional possível; em sendo assim, as diferenças de aceitabilidade estariam relacionadas a outros fatores, i.e. fatores não exclusivamente gramaticais.

\section{REFERÊNCIAS BIBLIOGRÁFICAS}

CAMARA JR., J.M. Estrutura da língua portuguesa. Petrópolis, Vozes, 1970.

CARreirA, M. B. Predicação e Ambiguidade de Projeção: Uma Teoria Unificada. 2015. 200 f. Tese de doutorado. Universidade Federal do Paraná, Curitiba, 2015.

CARREIRA, M. B., KNÖPFLE, A. Uma análise teórico-empírica de predicação secundária. Estudos Linguísticos, São Paulo, v. 42, n. 1, p.182-194, jan-abr 2013.

CARRIER, J.; J. H. RANDALL. The Argument Structure and Syntactic Structure of Resultatives. Linguistic Inquiry, v. 232, p.173-234, 1992.

CHOMSKY, N. Lectures on government and binding. Dordrecht, Foris, 1981.

CHOMSKY, N. Barriers. Cambridge, Mass, The MIT Press, 1986.

CHOMSKY, N. A minimalist program for linguistic theory. In: HALE, K.; KEYSER, S.J. (Orgs.). The view from Building 20. Cambridge, Mass., The MIT Press, 1993.

CHOMSKY, N. The Minimalist Program. Cambridge, Mass, The MIT Press, 1995.

CHOMSKY, N.; LASNIK, H. The theory of principles and parameters. In: JACOBS, J. et al. (Orgs.). Syntax: An international Handbook of Contemporary Research. Berlin, de Gruyter, 1993.

FOLLI, R.; GILLIAN, R. Prepositions and Results in Italian and English: An Analysis from Event Decomposition. In: Verkuyl, H.; De Swart, H.; Van Hout, A. (Orgs.). Perspectives on aspect. Dordrecht, Springer, 2005, p. 81-105.

FOLTRAN, M. J. G. D. As construções de predicação secundária no português do Brasil: aspectos sintáticos e semânticos. 1999. 205 f. Tese de Doutorado. Universidade de São Paulo, 1999.

GEUDER, W. Oriented adverbs: Issues in the lexical semantics of event adverbs. 2000. $220 \mathrm{f}$. Doctoral Dissertation, Universität Tübingen, 2000.

HOEKSTRA, T. Small clause results. Língua, v. 74, p.101-139, 1988.

HOEKSTRA, T. Small Clauses Everywhere. Ms., University of Leiden, 1991. 
HOEKSTRA, T. Small clauses everywhere. In: Sybesma, R.; Barbiers, S.; Dikken, M. Den; Doetjes, J.; Postma, G.; Wyngaerd, G.Vanden. (Orgs.). Arguments and Structure: Studies on the Architecture of the Sentence. Berlin, Mouton de Gruyter, 2004.

KNÖPFLE, A. Resultativas em línguas ocidentais germânicas: generalizações descritivas, descobertas empíricas e questões analíticas. 2014. 246 f. Tese de doutorado. Universidade Federal do Paraná, Curitiba, 2014.

KRATZER, A. Building resultatives. In: MAIENBAUM, C.; WÖLLSTEIN-LEISEN, A. (Orgs.). Event arguments in syntax, semantics, and discourse. Tübingen, Niemeyer, 2005.

LEVIN, B.; RAPPAPORT HOVAV, M. Unaccusativity: at the syntax-lexical semantics interface. Linguistic Inquiry, Monograph 26, Cambridge, Mass, The MIT Press, 1995.

LEVINSON, L. The roots of verbs. Doctoral Dissertation, New York University, 2007.

LEVINSON, L. Arguments for pseudo-resultative predicates. Natural Language and Linguistic Theory, v. 28, n. 1, 2010.

LOBATO, L. Afinal, existe a construção resultativa em português? In: NEGRI, L.; FOLTRAN; M. J.; PIRES DE OLIVEIRA, R. (Orgs.). Sentido e Significação. São Paulo, Contexto, 2004.

PARSONS, T. Events in the semantics of English. Cambridge, MA, MIT Press, 1990. RIZZI, L. Relativized Minimality. Cambridge, Mass, The MIT Press, 1990.

Recebido em 01/02/2017

Aceito em 11/07/2017

Publicado em 27/06/2017 